\title{
Wood ant assemblages of Formica rufa group on lake islands and in mainland woodland in Central Finland
}

\author{
Jouni Sorvari
}

Sorvari, J. 2018: Wood ant assemblages of Formica rufa group on lake islands and in mainland woodland in Central Finland. - Entomol. Fennica 29: 21-29.

Associations of island size and isolation on the occurrence and species richness of five wood ant species of the Formica rufa group (F. rufa, F. aquilonia, F. lugubris, F. polyctena and F. pratensis) was tested in the Lake Konnevesi archipelago in Central Finland. In addition, the species composition was compared to that of mainland forests of the same region. Island isolation had no associations with the wood ant occurrence in this archipelago, but for most species, increasing island size was positively associated with the occurrence probability. According to the findings among the five species, Formica lugubris is the best adapted for insular living. There was a positive species-area relationship as the species richness of wood ants increased with an increasing island size. The island community of wood ants was dominated by colonies of the monogynous (single queen) species whereas the mainland community was dominated by those of polygynous (multiple queen) species.

J. Sorvari, Department of Environmental and Biological Sciences, University of Eastern Finland, P.O. Box 1627, FI-70211 Kuopio, Finland (current address); Department of Biology, Section of Ecology, University of Turku, FI-20014 Turku, Finland; E-mail: jouni.sorvari@uef.fi

Received 24 January 2017, accepted 3 May 2017

\section{Introduction}

According to island biogeography theory (MacArthur \& Wilson 1967), a large island should have higher species richness than a small island (with all remaining independent variables equals). This may be due to the fact that large islands may have more ecological niches and that the large surface itself eases colonisation. This should also be visible on an individual species level as a species' probability of occurrence would be higher on large islands. Numerous studies show a higher number of species on large islands compared to smaller ones (e.g. Morrison 1997, Rizali et al. 2010, Clark et al. 2011, Morrison 2016).
Ideally, island biogeographical studies are conducted with a set of species representing similar life history strategies, for example a group of closely related species. An example of this kind of a species group is the European mound-building wood ants of the Formica rufa group. It consists of six closely related species belonging to the subgenus Formica s. str., namely: Formica rufa Linné, 1761; F. aquilonia Yarrow, 1955; F. lugubris Zetterstdt, 1840; F. paralugubris Seifert, 1996; F. polyctena Förster, 1850 and F. pratensis Retzius, 1783. A possible seventh European species has been recently reported to exist in the Swiss Alps (Bernasconi et al. 2011). These species occur mostly in conifer forests or forest margins, although $F$. pratensis also commonly oc- 
cupy meadows or other open areas (Collingwood 1979, Rosengren \& Pamilo 1983). Five of the species live in Finland. The most common species are $F$. aquilonia and $F$. lugubris, which seem to live in all regions in Finland. The rest, F. rufa, $F$. polyctena and $F$. pratensis, are generally restricted to the southern part of the country (e.g. Stockan et al. 2016).

The colonies are populous as the worker population ranges from 100,000 to several million in a mature colony, depending on the species and the colony structure (Collingwood 1979, Rosengren \& Pamilo 1983, Seifert 1991). Within the group, F. aquilonia and $F$. polyctena are obligatorily polygynous (i.e. there are always several to thousands of egg-laying females in a colony) and they are normally polydomous, in other words they have several colonies in a non-competitive relationship, peacefully sharing the resources (Collingwood 1979, Rosengren \& Pamilo 1983). The others, F. rufa, F. lugubris and F. pratensis, seem to be facultatively polygynous, in other words they can switch tactics from monogyny (a single egg-laying female in a colony) and monodomy (a colony inhabiting a single nest, aggressive to all aliens and conspecifics) to polygyny and polydomy (Rosengren et al. 1993). In Finnish populations, however, they all tend to be monogynous or at least monodomous (Rosengren \& Pamilo 1983, Rosengren et al. 1993).

All species of the group establish new colonies by dispersal flight followed by a colony founding by means of temporal social parasitism, i.e. the dispersing queen takes over a colony of one of the species of the subgenus Serviformica, e.g. F. fusca Linnaeus or F. lemani Bondroit; however, polygynous colonies are able to establish new nests by colony budding (Rosengren \& Pamilo 1983). The tendency for short-range dispersal in connection with the tendency of colony splitting in polygynous species may affect the dispersal and colonisation ability of species. In a study by Mabelis (1994), it has been shown that polygynous $F$. polyctena was common in large forest patches whereas smaller, isolated forest patches were typically dominated by monodomous F. rufa. In the same study, it was also shown that larger forest patches had more species of wood ants than smaller patches. In addition, Vepsäläinen and Pisarski (1982) showed that wood ants generally preferred large islands over smaller islands in the Baltic Sea archipelago since large islands have increased cover of suitable habitats.

The species of $F$. rufa group are specialists of late succession forests, especially the polygynous species $F$. aquilonia and $F$. polyctena that tend to nest in large mature forests (Rosengren \& Pamilo 1983). Monogynous species generally prefer forests and forest edges, but are able to colonise forests of younger successional stages than the polygynous species (Punttila 1996).

On a local scale, such as in an archipelago, factors influencing the island biogeography of the wood ant species of the F. rufa group could be island size, isolation and habitat type (e.g. forested vs. rocky). In forested islands of this study, I investigated 1) whether isolation and island size have a different association with the occurrence of wood ants that use different strategies (monogyny and polygyny) and 2) whether wood ant assemblages have a different species composition on islands compared to that of the surrounding woodland assemblages on the mainland.

\section{Materials and methods}

A sample of 74 forest covered islands of various sizes and 133 forest stands were surveyed on western part of the Lake Konnevesi and the adjacent mainland around Konnevesi Research Station (the University of Jyväskylä; WGS84 coordinates: N 62³6.9570', E $26^{\circ} 20.7972 '$ ') in central Finland during 1999-2001. Wood and workers (10-30/nest) were sampled from the top of all nest mounds found in the study area. The ants were stored in $70 \%$ ethanol. Species identification was based on the keys of Collingwood (1979) and Douwes (1995) and on ten workers from each colony. All five wood ants present in Finland were found in the study area, but only one nest of $F$. pratensis (Table 1).

The nearest distance from the island to the mainland (nearest mainland distance: NMD) and the nearest distance to any woodland covered terrestrial biome, mainland or island (but not treeless rocky islets) (ND), were measured. Connectivity was calculated as the mean of in total three NMDs and/or NDs. If an island was located in a 
Table 1. Numbers of islands and forest plots settled by wood ant species (with expected frequency based on total frequencies in parentheses) on Lake Konnevesi islands $(\mathrm{N}=74)$ and in mainland forests of Konnevesi-Laukaa region $(N=133)$ in Central Finland. $\mathrm{P}=$ polygyny, $\mathrm{M}=$ monogyny. In the lower part of the table, species using a polygyny strategy and monogyny strategy are pooled and their expected frequencies (in parentheses) were calculated separately from the species-level frequencies.

\begin{tabular}{llll}
\hline & P/M & $\begin{array}{l}\text { Lake } \\
\text { islands }\end{array}$ & $\begin{array}{l}\text { Mainland } \\
\text { forest plots }\end{array}$ \\
\hline F. aquilonia & $\mathrm{P}$ & $5(20.2)$ & $61(45.8)$ \\
F. lugubris & $\mathrm{M}$ & $16(6.1)$ & $4(13.9)$ \\
F. polyctena & $\mathrm{P}$ & $3(6.1)$ & $17(13.9)$ \\
F. pratensis & $\mathrm{M}$ & $1(0.3)$ & $0(0.7)$ \\
F. rufa & $\mathrm{M}$ & $12(4.3)$ & $2(9.7)$ \\
Polygynous & & $8(26.3)$ & $78(59.7)$ \\
Monogynous & & $29(10.7)$ & $6(24.3)$ \\
\hline
\end{tabular}

bay, the distances to the different shorelines of the mainland were measured using $90^{\circ}$ divergence between measured lines, starting from the ND. In addition, the area of the islands was measured. The measurements were made using a map service (www.retkikartta.fi of Metsähallitus, State Forest Enterprise, Finland).

Based on the measured continuous area coverage of islands, the islands were divided into three different size categories following the classification of Vepsäläinen and Pisarski (1982): small islands $(\leq 0.5 \mathrm{ha})$, medium-sized islands $(>0.5-<4 \mathrm{ha})$ and large islands ( $\geq 4 \mathrm{ha})$. Of the studied islands, 30 represented small islands, 26 were medium-sized islands and 18 were large islands.

The mainland forest stands were a subsample of the study plots used in bird studies of the insectivorous treecreeper (Certhia familiaris Linnae- us) from 1999 to 2000 (e.g. Jäntti et al. 2007). Within each study stand, a circular study plot of $\varnothing$ $100 \mathrm{~m}$ was searched for wood ants. The minimum distances between neighbouring study plots varied between $233 \mathrm{~m}$ and 3,905 $\mathrm{m}$ (mean $\pm \mathrm{SD}$ : $1,054.0 \mathrm{~m} \pm 690.4)$. The study plots were distributed on a landscape of $1,150 \mathrm{~km}^{2}$ in KonnevesiLaukaa region.

The forests were mainly dominated by Norway spruce (Picea abies (L.) H. Karst.) mixed with Scots pine (Pinus sylvestris Linnaeus) and birches (Betula pubescens Ehrh. and B. pendula Roth) both on the mainland and on the islands. The forests were mostly similar between the mainland and islands, but some of the island forests were more open due to rocky habitats.

In this study, the occurrence (present vs. absent) of wood ant assemblages was studied instead of the abundance data of the nest mounds. This is because using abundance would cause some bias to the results since polygynous/polydomous species would anyway have multiple nests. In addition, a couple of monodomous $F$. lugubris nests on a medium size island may give higher abundance per area than e.g. four nests of F. aquilonia on a large island.

All analyses were run using SAS statistical software version 9.4 (SAS INC, Cary, IL, USA). Generalized linear models (PROC GLIMMIX) using binomial distribution $\left(\mathrm{GLM}_{\text {BINOMIAL }}\right)$ and the logit link function were used for the analyses of the probability of occurrence, and GLM using Poisson distribution $\left(\mathrm{GLM}_{\text {POISSON }}\right)$ with the log link function were used for the analysis of species richness of wood ants on the islands. All distance measurements were inter-correlated, whereas island area only correlated with the connectivity distance (Table 2). Due to this high level of intercorrelation, different sets of models were carried out. Connectivity was always analysed in single

Table 2. Pearson correlation matrix of the distance variables (NMD: nearest mainland distance, ND: nearest distance to suitable terrestrial habitat, connectivity) and island area.

\begin{tabular}{|c|c|c|c|}
\hline & ND & Connectivity & Island area \\
\hline $\begin{array}{l}\text { NMD } \\
\text { ND } \\
\text { Connectivity }\end{array}$ & $r=0.263, p=0.02$ & $\begin{array}{l}r=0.295, p=0.01 \\
r=0.787, p<0.0001\end{array}$ & $\begin{array}{l}r=-0.182, p=0.12 \\
r=-0.107, p=0.36 \\
r=-0.236, p=0.04\end{array}$ \\
\hline
\end{tabular}


Table 3. Results of binomial logistic regression models for the association of both distance predictors (excl. connectivity) and island area with the occurrence of different wood ant species on islands. The strongest model is evaluated by using each model's AIC value (smaller is better). ND = nearest distance to suitable terrestrial habitat; NMD = nearest mainland distance. Best models of each species are set in bold.

\begin{tabular}{lllll}
\hline & Model & AIC & Island area & Second term \\
\hline F. aquilonia & area & 35.85 & $F_{1,72}=5.25, p=0.025$ & - \\
& area \& ND & 37.76 & $F_{1,71}=5.06, p=0.028$ & $F_{1,71}=0.08, p=0.78$ \\
& area \& NMD & 37.84 & $F_{1,71}=4.47, p=0.038$ & $F_{1,71}=0.02, p=0.90$ \\
F. polyctena & area & 24.90 & $F_{1,72}=4.78, p=0.032$ & - \\
& area \& ND & 26.52 & $F_{1,71}=4.54, p=0.037$ & $F_{1,71}=0.22, p=0.64$ \\
F. rufa & area \& NMD & $\mathbf{2 3 . 6 3}$ & $F_{1,71}=\mathbf{5 . 6 1} p=\mathbf{0 . 0 2 1}$ & $\boldsymbol{F}_{1,71}=\mathbf{2 . 9 9 , p = 0 . 0 8 8}$ \\
& area & $\mathbf{6 3 . 1 4}$ & $F_{1,72}=\mathbf{6 . 0 8}, p=\mathbf{0 . 0 1 6}$ & - \\
& area \& ND & 64.99 & $F_{1,71}=6.11, p=0.016$ & $F_{1,71}=0.16, p=0.69$ \\
F. lugubris & area \& NMD & 64.04 & $F_{1,71}=4.74, p=0.033$ & $F_{1,71}=0.98, p=0.32$ \\
& area & 78.42 & $F_{1,72}=\mathbf{2 . 8 9} p=0.094$ & - \\
& area \& ND & 80.23 & $F_{1,71}=3.00, p=0.088$ & $F_{1,71}=0.20, p=0.66$ \\
& area \& NMD & 80.40 & $F_{1,71}=2.65, p=0.11$ & $F_{1,71}=0.02, p=0.88$ \\
\hline
\end{tabular}

predictor models. NMD and ND could be analysed together with island area but not with each other. Significant predictors in the double predictor models were further analysed in single predictor models in binomial regression analysis in generalized linear models. The strength of the used double predictor models were compared with the significant single predictor models using Akaike's information criterion (AIC; smaller is better). In addition, the structure of the island assemblages and mainland forest assemblages were compared using likelihood ratio tests.

\section{Results}

Of the 74 islands, $F$. rufa was present on 12 islands, $F$. aquilonia on five islands, $F$. lugubris on 16 islands, $F$. polyctena on three islands, and $F$. pratensis on only one island (Table 1 ). Due to the rarity of the species, F. pratensis was not analysed in single species models. Twenty-four islands were inhabited by wood ants leaving fifty islands uninhabited.

Connectivity (mean \pm SD: $224.0 \mathrm{~m} \pm 146.6$ $\mathrm{m})$ had no association with the occurrence of the wood ants $\left(\mathrm{GLM}_{\text {BINOMIAL }}\right.$, F. rufa: $F_{1,72}=0.03, p=$ $0.86 ; F$. aquilonia: $F_{1,72}=0.75, p=0.39 ; F$. lugubris: $F_{1,72}=0.33, p=0.57 ;$ F. polyctena: $F_{1,72}=$ $0.19, p=0.67)$. Neither ND (mean \pm SD: $107.8 \mathrm{~m}$ $\pm 125.9 \mathrm{~m}$ ) nor NMD (mean \pm SD: $678.2 \mathrm{~m} \pm$
$557.3 \mathrm{~m}$ ) had any association with the occurrence of different wood ant species, but the probability of occurrence of F. rufa, F. aquilonia and $F$. polyctena increased with increasing island size while $F$. lugubris did not show such an association (Table 3, Fig. 1). The single predictor model for island area was stronger than the two predictor models (island area \& NMD, island area \& ND) in F. rufa and in F. aquilonia (the AIC value is smaller), whereas for $F$. polyctena island area coupled with NMD was a stronger model than island area as a single predictor (with AIC 23.63 and 24.90 respectively, Table 3).

Since the aspeceis of $F$. rufa wood ant group are colony-type polymorphic, the data allowed the pooling of the species over the colony type. The species adapted to the monogyny strategy (pooled F. rufa, F. lugubris and F. pratensis) and polygyny (pooled $F$. aquilonia and $F$. polyctena), and all the wood ants combined increased their probability of occurrence with increasing island size, whereas such associations were not found with ND and NMD in this archipelago (Table 4, Fig. 2). In addition, connectivity had no such associations either $\left(\mathrm{GLM}_{\text {BINOMIAL }}\right.$, monogyny: $F_{1,72}$ $=0.14, p=0.71$; polygyny: $F_{1,72}=0.94, p=0.34$; all combined: $F_{1,72}=0.35, p=0.56$ ).

The number of wood ant species increased with increasing island size (Fig. 3), and whereas ND and NMD had no associations with species richness, the island area had (Table 4). The stron- 


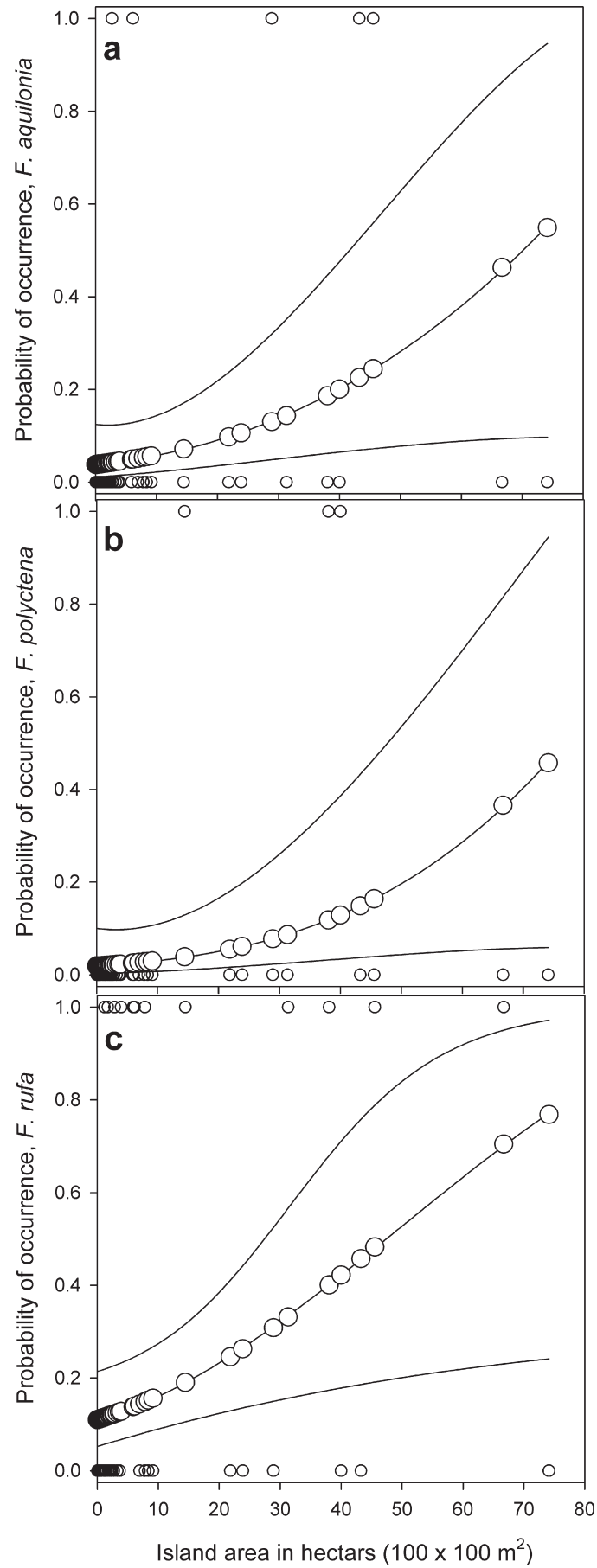

Fig. 1. Probability of occurrence increased with an increase in island size for three wood ant species. $-a$. Formica aquilonia. - b. F. polyctena. - c. F. rufa. Predicted values (large circles) were obtained from a binomial generalized linear model with $95 \%$ confidence limits. Small circles represent the observations.
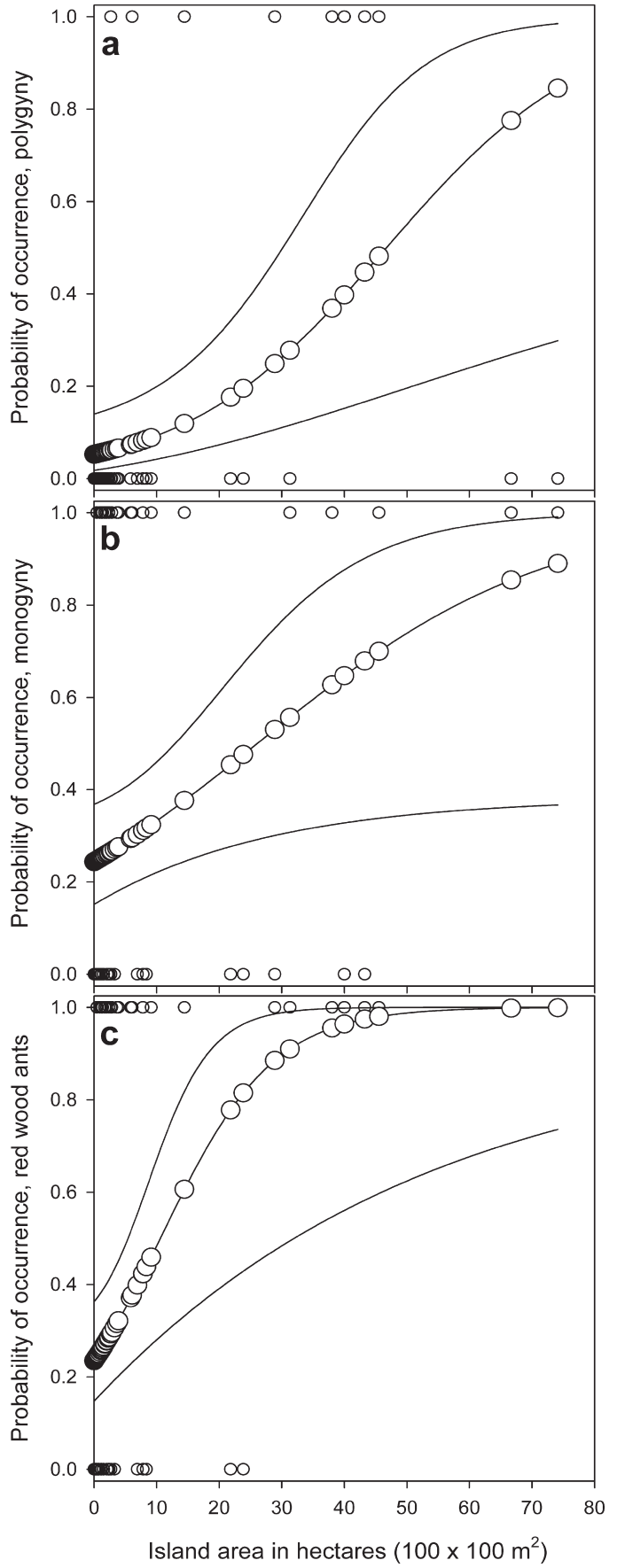

Fig. 2. Probability of occurrence increased with an increase in island size for the following wood ant groupings. - a. Polygynous species ( $F$. aquilonia and $F$. polyctena). - b. Monogynous species ( $F$. rufa, $F$. lugubris and $F$. pratensis). - c. All species combined. Predicted values (large circles) were obtained from a binomial generalized linear model with $95 \%$ confidence limits. Small circles represent the observations. 
Table 4. Results of binomial logistic regression models for the association of distance predictors (excl. connectivity) and island area with the occurrence of polygynous species ( $F$. aquilonia and $F$. polyctena), monogynous species ( $F$. rufa, F. lugubris and F. pratensis) and all wood ant species combined. In addition, the results of Poisson regression analyses for the association of the same set of predictors with the species richness of wood ants on the islands are presented. The strongest model is evaluated by using model's AIC value (smaller is better). ND = nearest distance to a suitable terrestrial habitat, $\mathrm{NMD}=$ nearest mainland distance. Best models are set in bold.

\begin{tabular}{|c|c|c|c|c|}
\hline & Model & AIC & Island area & Second term \\
\hline Polygyne & $\begin{array}{l}\text { area } \\
\text { area \& ND } \\
\text { area \& NMD }\end{array}$ & $\begin{array}{l}44.20 \\
45.95 \\
45.10\end{array}$ & $\begin{array}{l}F_{1,72}=8.97, p=0.0038 \\
F_{1,71}=8.66, p=0.0044 \\
F_{1,71}^{\prime}=9.59, p=0.0028\end{array}$ & $\begin{array}{l}- \\
F_{1,71}=0.19, p=0.66 \\
F_{1,71}=1.14, p=0.29\end{array}$ \\
\hline Monogyne & $\begin{array}{l}\text { area } \\
\text { area \& ND } \\
\text { area \& NMD }\end{array}$ & $\begin{array}{l}89.18 \\
90.56 \\
91.15\end{array}$ & $\begin{array}{l}\boldsymbol{F}_{1,72}=\mathbf{5 . 2 2}, \boldsymbol{p}=\mathbf{0 . 0 2 5} \\
F_{1,71}=5.47, p=0.022 \\
F_{1,71}=5.00, p=0.029\end{array}$ & $\begin{array}{l}- \\
F_{1,71}=0.65, p=0.42 \\
F_{1,71}=0.03, p=0.87\end{array}$ \\
\hline Wood ants & $\begin{array}{l}\text { area } \\
\text { area \& ND } \\
\text { area \& NMD }\end{array}$ & $\begin{array}{l}82.65 \\
84.38 \\
84.64\end{array}$ & $\begin{array}{l}F_{1,72}=7.02, p=0.0096 \\
F_{1,71}=7.24, p=0.0089 \\
F_{1,71}=7.16, p=0.0092\end{array}$ & $\begin{array}{l}\bar{F}_{1,71}=0.28, p=0.60 \\
F_{1,71}=0.05, p=0.82\end{array}$ \\
\hline Species richness & $\begin{array}{l}\text { area } \\
\text { area \& ND } \\
\text { area \& NMD }\end{array}$ & $\begin{array}{l}131.01 \\
132.97 \\
132.95\end{array}$ & $\begin{array}{l}F_{1,72}=18.35, p<0.0001 \\
F_{1,71}=18.39, p<0.0001 \\
F_{1,71}=15.29, p=0.0002\end{array}$ & $\begin{array}{l}\bar{F}_{1,71}=0.05, p=0.83 \\
F_{1,71}=0.06, p=0.81\end{array}$ \\
\hline
\end{tabular}

gest model was with the island area as a single predictor (Smallest AIC value; Pearson correlation $r=0.405, p=0.0003$ ). Connectivity had no association with the species richness of wood ants in this archipelago $\left(\mathrm{GLM}_{\text {POISSON }}, F_{1,72}=0.66, p=\right.$ 0.42 ).

When the classification of island size was used, the colonies of F. rufa, F. aquilonia and $F$. polyctena occurred mostly on large islands, whereas the occurrence of the colonies of $F$. lugubris peaked in medium-sized islands (Fig. 4). The latter result explains why the probability of occurrence was not significantly associated with island size for F. lugubris (Table 3).

The structure of wood ant assemblages on Lake Konnevesi islands was dominated by monogynous species whereas the mainland forest habitats were more commonly inhabited by the polygynous species (species data: likelihood ratio test, $G^{2}=65.18, p<0.0001$; pooled data: $G^{2}=$ 63.70, $p<0.0001$; Table 1).

\section{Discussion}

Mabelis (1994) found monogynous species ( $F$. rufa, $F$. pratensis) more frequently in small isolated forests and polygynous species ( $F$. polyctena) in large forest patches. The results of the present study highlight the positive effect of the large size of a suitable habitat patch or large forested islands, not only for the polygynous species (F. aquilonia, F. polyctena) but also for monogynous $F$. rufa. The latter species was found by Dekonink et al. (2010) to favour also large

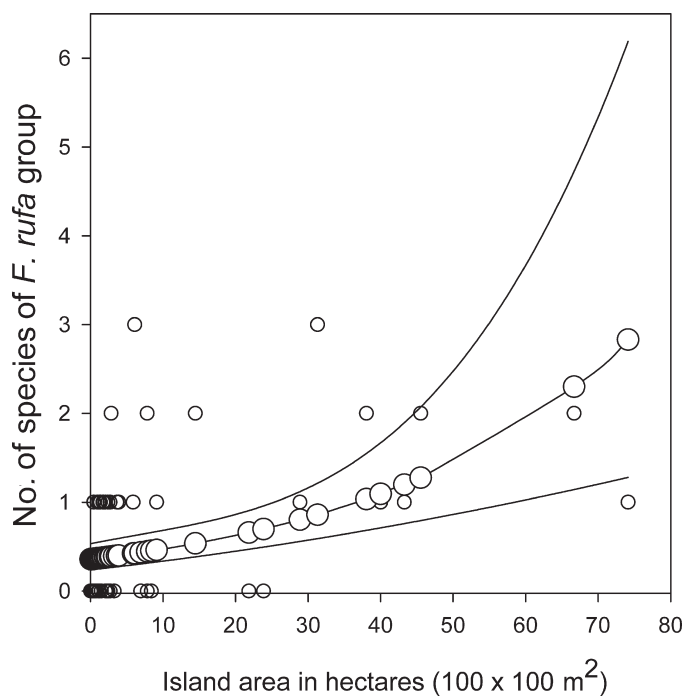

Fig. 3. Number of wood ant species increased with increase in island size. Predicted values (large circles) were obtained from a Poisson regression generalized linear model with $95 \%$ confidence limits. Small circles represent the observations. 
Fig. 4. Proportional frequency of species observations in small ( $<0.5$ ha), mediumsized (0.5-4 ha) and large ( $>4$ ha) islands. Numbers above bars represent numbers of islands occupied by each species. Most observations of Formica aquilonia, F. polyctena and $F$. rufa were from large islands whereas the occurrence peaked for $F$. lugubris on medium-sized islands. Of the studied islands, 30 were small islands, 26 were medium-sized islands and 18 were large islands.

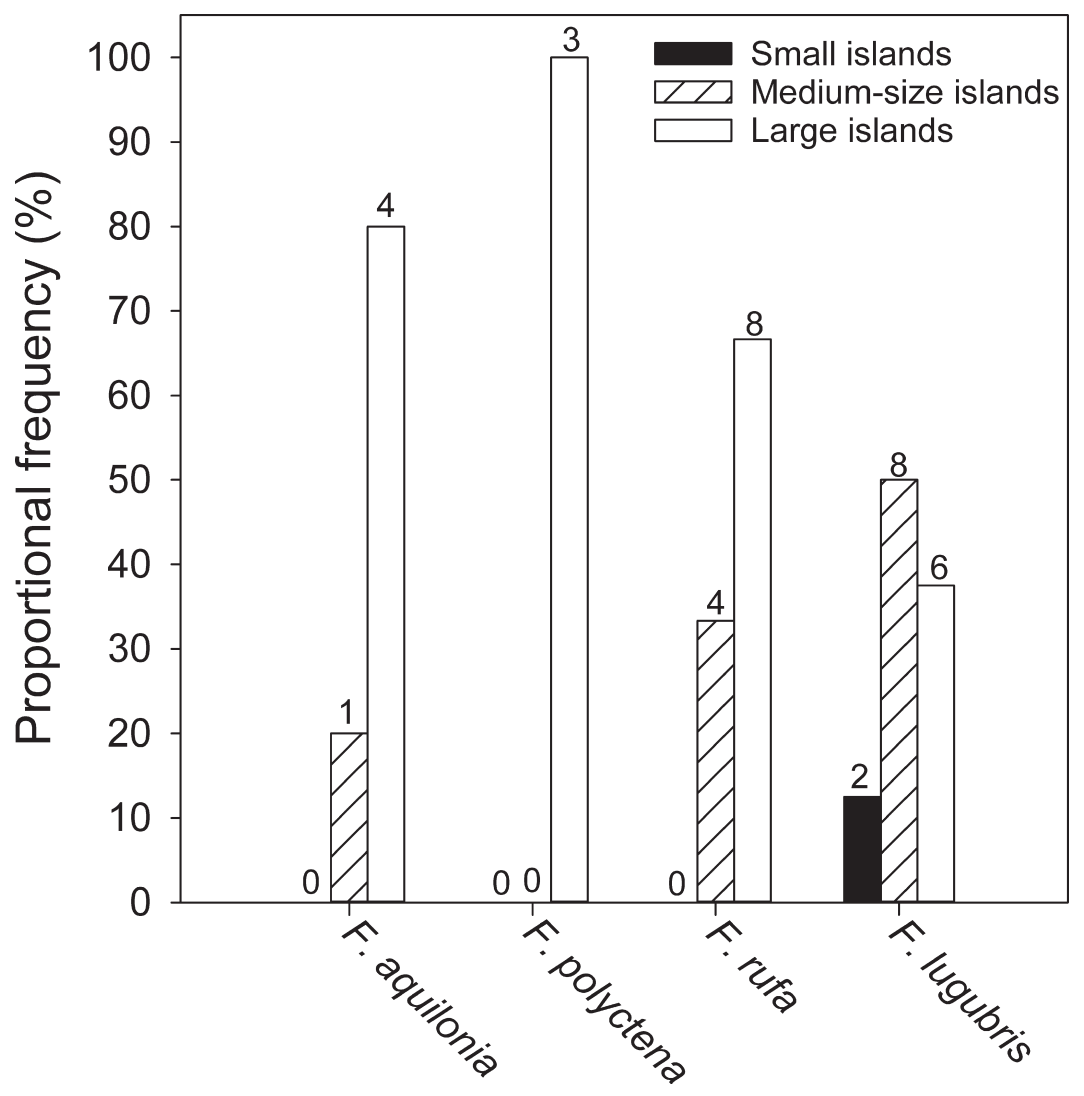

pine forests. On the other hand, the occurrence of the most common wood ant, F. lugubris, on the islands did not increase linearly with island size. The meadow ant, $F$. pratensis, was only present on one island (one nest), and thus, no conclusions about that species could be made based on the data of this study.

Since none of the distance variables (NMD, ND or connectivity) had significant associations with the occurrence of wood ant species and wood ant species richness, no evidence of distance decay effect was found. Probably the distances were too short to cause a significant dispersal barrier. However, in the case of polygynous $F$. polyctena, the NMD contributed to the habitat selection model at some level. Unlike this study, Clark et al. (2011) found significant decrease of ant species richness with island isolation in an archipelago located in the Northeast USA.

Rizali et al. (2010) found a positive speciesarea relationship of ants in an Indonesian archipelago. Similarly Clark et al. (2011) found a posi- tive species-area relationship in an archipelago in the Northeast USA. Using a restricted set of ant species, five wood ant species, a similar trend was found here as the number of wood ant species increased with an increase in island area. Interestingly, wood ant nests can act as habitat islands themselves. Päivinen et al. (2004) found an increase in the myrmecophilous beetle species richness with increasing volume of nest mounds. In addition, the probability of the occurrence of the shiny guest ant, Formicoxenus nitidulus (Nylander) (a xenobiont living in wood ant nest mounds), increased with increasing nest mound volume (Dietrich 1997, Ölzant 2001, Härkönen \& Sorvari 2017).

Vepsäläinen and Pisarski (1982) studied island ant populations in the Baltic Sea archipelago close to the Hanko peninsula area in Finland. They found that most of the wood ant species were only present on large islands but $F$. aquilonia was also found on medium-sized islands. The same size classification was used here, and $F$. 
polyctena was only found on large islands, whereas $F$. rufa, F. aquilonia and F. lugubris were found on large and medium-sized islands $-F$. lugubris was even found on small islands. The frequency peaked for F. aquilonia, F. rufa and of course $F$. polyctena on large islands, whereas the frequency of $F$. lugubris peaked on medium-sized islands. The ability of F. lugubris to nest on islands of all size classes is likely to explain the commonness of F. lugubris in the Lake Konnevesi archipelago.

Ants typically colonise new areas in certain sequences and first colonisers, the pioneers, are often replaced by stronger competitors or specialists of later successional stages. An example of this from Finnish island habitats is the species pair in the genus Lasius where L. niger (Linnaeus) is able to colonise islands rapidly but is largely replaced by its sister species $L$. platythorax Seifert during habitat succession (Czechowski et al. 2013). The wood ants of the $F$. rufa group are late successor species. They are temporal parasites of Formica species belonging to a different subgenus, Serviformica, such as F. fusca and F. lemani. The host species found their colonies independently and are typical species of earlier forest succession stages. Therefore, colonisation of the ant species of the $F$. rufa group on islands is always dependent on the presence of Serviformica colonies. Another feature in the F. rufa group that makes their colonisation on islands hard is that the species are territorial and do not tolerate cospecifics and other members of the group in the vicinity of their nests, thus, possible colonizer queens of the species group may be eliminated. This certainly affects the colonisation success of other wood ant species, especially in limited forest areas of small islands.

Punttila (1996) found that F. lugubris is the most common wood ant species in the young successional stages of forests as well as in small old-forest fragments. Based on Punttila's results and the present study, it can be suggested that the species is the most effective coloniser among the wood ants in Finland and most flexible when it comes to habitat selection.

Czechowski and Vepsäläinen (2009) artificially introduced a colony of $F$. polyctena on a $<0.2$ ha island where the colony survived over 22 years. The island had only very few small trees, thus, the colony could survive, but had not enough resources to produce sexual offspring. In such situation, polygynous species may be completely dependent on the adoption of new queens from mainland or other islands. However, monogynous species, such as F. lugubris, may be able to complete the colony cycle and produce new sexual generation, due to their ability to live in earlier successional stages of forests.

In this study, the monogynous species were found more frequently than expected on islands and less frequently than expected in the mainland forest plots, whereas the opposite was found for the polygynous species. Thus, the structure of wood ant species communities was found to differ between the island populations and the mainland forests. This is probably due to the different dispersal and colonisation ability between the monogynous and polygynous species.

In an earlier work, Mabelis (1994) suggested that while monogynous $F$. rufa may have a greater chance of becoming extinct than polygynous colonies of $F$. polyctena, it may be compensated for by its higher colonisation rate. In the present study, the mainland populations were dominated by the polygynous species, $F$. aquilonia and $F$. polyctena, probably because of their good survival over the years since having a high number of queens. They frequently adopt new queens and polydomy makes the colonies persistent over long periods. In the island populations, polygynous species were found on relatively few islands compared to the monogynous ones, probably due to their poorer dispersal and colonisation abilities. Abandoned single nests were commonly found on the islands, which are likely to be the remnants of extinct monogynous colonies. The present results seem to support Mabelis' suggestion that the higher extinction rate of monogynous species is compensated for by their higher colonisation rates.

In conclusion, it was found that the structure of the wood ant community is different on lake islands than on the mainland. Despite the high extinction propensity of the monogynous (single queen) colonies, the monogynous species were common on islands, possibly due to their better colonisation ability compared to the polygynous species. In addition, it seems that $F$. lugubris is able to colonise and survive on small islands, 
which may make it also tolerant to forest fragmentation in mainland forests.

Acknowledgements. I am grateful to Jussi Päivinen and Heikki Helle for their assistance with Lake Konnevesi island populations and Ari Jäntti, Esa Huhta and the late Harri Hakkarainen for assistance with mainland populations. In addition, I am grateful to the personnel of the Konnevesi Research Station (University of Jyväskylä) for maintenance of the researchers during the field trips. Two anonymous reviewers gave constructive comments to the manuscript. The English language was checked by professional proof-reader from Lingsoft Company. The study was funded by Oskar Öflund's Foundation.

\section{References}

Bernasconi, C., Cherix, D., Seifert, B. \& Pamilo, P. 2011: Molecular taxonomy of the Formica rufa group (red wood ants) (Hymenoptera: Formicidae): a new cryptic species in the Swiss Alps? - Myrmecological News 14: $37-47$.

Clark, A. T, Rykken, J. J. \& Farrell, B. D. 2011: The Effects of Biogeography on Ant Diversity and Activity on the Boston Harbor Islands, Massachusetts, U.S.A. PLoS ONE 6(11): e28045.

Collingwood, C. A. 1979: The Formicidae (Hymenoptera) of Fennoscandia and Denmark. - Fauna Entomologica Scandinavica 8: 1-174.

Czechowski, W. \& Vepsäläinen, K. 2009: Territory size of wood ants (Hymenoptera: Formicidae): a search for limits of existence of Formica polyctena Först., an inherently polygynic and polycalic species. - Annales Zoologici 59(2): 179-187.

Czechowski, W., Vepsäläinen, K. \& Radchenko, A. 2013: Ants on skerries: Lasius assemblages along primary succession. - Insectes Sociaux 60: 147-153.

Dekonink, W., Hendrickx, F., Grootaerd, P. \& Maelfait, J.P. 2010: Present conservation status of red wood ants in north-western Belgium: worse than previously, but not a lost cause. - European Journal of Entomology 107: 209-218.

Dietrich, C. O. 1997: Quantifizierungsversuch des Vorkommens der Glänzenden Gastameise, Formicoxenus nitidulus (Nyl.) bei der Gebirgswaldameise Formica lugubris Zett. am Muttersbergmassiv (Österreich, Vorarlberg, Lechtaler Alpen). - Verhandlungen der Zoologisch-Botanischen Gesellschaft in Wien 134: 119-132.

Douwes, P. 1995: Sveriges myror. — Entomologisk Tidskrift 116: 83-99.

Härkönen, S. K. \& Sorvari, J. 2017: Effect of host species, host nest density and nest size on the occurrence of the shining guest ant Formicoxenus nitidulus (Hymenop- tera: Formicidae). - Journal of Insect Conservation 21: $477-485$.

Jäntti, A., Suorsa, P., Hakkarainen, H., Huhta, E. \& Kuitunen, A. 2007: Within territory abundance of red wood ants Formica rufa is associated with the body condition of nestlings in the Eurasian treecreeper Certhia familiaris. - Journal of Avian Biology 38: 619-624.

Mabelis, A. 1994: Flying as a survival strategy for wood ants in a fragmented landscape (Hymenoptera, Formicidae). - Memorabilia Zoologica 48: 147-170.

MacArthur, R. H. \& Wilson, E. O. 1967: The Theory of Island Biogeography. Princeton University Press, Princeton, NJ, USA. 203 pp.

Morrison, L. W. 1997: The insular biogeography of small Bahamian cays. - Journal of Ecology 85: 441-454.

Morrison, L. W. 2016: The ecology of ants (Hymenoptera: Formicidae) on islands. - Myrmecological News 23: $1-14$.

Ölzant, S. 2001: Freilandökologische Untersuchungen an der Gastameise Formicoxenus nitidulus (NYLANDER, 1846) unter besonderer Berücksichtigung der Nesttemperatur (Hymenoptera: Formicidae). — Myrmecologische Nachricten (Myrmecological News) 4: $1-10$.

Päivinen, J., Ahlroth, P., Kaitala, V. \& Suhonen, J. 2004: Species richness, abundance and distribution of myrmecophilous beetles in nests of Formica aquilonia ants. - Annales Zoologici Fennici 41: 447-454.

Punttila, P. 1996: Succession, forest fragmentation, and the distribution of wood ants. - Oikos 75: 291-298.

Rizali, A., Lohman, D. J., Buchori, D., Prasetyo, L. B., Triwidodo, H., Bos, M. M., Yamane, S. \& Schulze, C. H. 2010: Ant communities on small tropical islands: effects of island size and isolation are obscured by habitat disturbance and 'tramp' ant species. - Journal of Biogeography 37: 229-236.

Rosengren, R. \& Pamilo, P. 1983: The evolution of polygyny and polydomy in mound-building Formica ants. Acta Entomologica Fennica 42: 65-77.

Rosengren, R., Sundström, L. \& Fortelius, W. 1993: Monogyny and polygyny in Formica ants: the result of alternative dispersal tactics. - In: Keller, L. (ed.), Queen number and sociality in insects: 308-333. Oxford University Press, Oxford, UK. 439 pp.

Seifert, B. 1991: The phenotypes of the Formica rufa complex in East Germany. - Abhandlungen und Berichte des Naturkundemuseums Görlitz 65: 1-27.

Stockan, J., Robinson, E. J. H., Trager, J. C., Yao, I. \& Seifert, B. 2016: Introducing wood ants: evolution, phylogeny, identification and distribution. - In: Stockan, J. A. \& Robinson, E. J. H. (eds), Wood Ant Ecology and Conservation: 1-36. Cambridge University Press, Cambridge, UK. 304 pp.

Vepsäläinen, K. \& Pisarski, B. 1982: Assembly of island ant communities. - Annales Zoologici Fennici 19: $327-335$. 